\title{
TURBULENT FILM CONDENSATION OF PURE VAPORS FLOWING NORMAL TO A HORIZONTAL CONDENSER TUBE - CONSTANT HEAT FLUX AT THE TUBE WALL
}

\author{
B. Vijaya Lakshmi ${ }^{1 *}$, T. Subrahmanyam ${ }^{2}$, V. Dharma Rao ${ }^{1}$ and K.V. Sharma ${ }^{3}$ \\ ${ }^{1}$ Department of Mechanical Engineering \\ Faculty of Mechanical Engineering, GVP College of Engineering, \\ Visakhapatnam, India; Phone: 09493529796 \\ Email: vijaya_bathula@hotmail.com \\ ${ }^{2}$ Department of Mechanical Engineering \\ Faculty of Mechanical Engineering, Andhra University, Visakhapatnam, India; \\ ${ }^{3}$ Department of Mechanical Engineering, \\ Faculty of Mechanical Engineering, University of Malaysia, Pahang, \\ 26600 Pekan, Pahang, Malaysia
}

\begin{abstract}
A mathematical model was developed for the study of external turbulent film condensation of pure vapours flowing downward and normal to the axis of the condenser tube with constant heat flux conditions maintained at the tube wall. The magnitude of interfacial shear was estimated for a given external flow condition of the vapour with the help of Colburn's analogy. The average condensation heat transfer coefficients for different system conditions were evaluated. The present theory was compared with the available experimental and theoretical data in the literature and was found to be satisfactory.
\end{abstract}

Keywords: Film condensation; turbulent flow; condenser tube; interfacial shear.

\section{INTRODUCTION}

The phenomenon of condensation of vapours flowing around a condenser tube is of practical significance in high pressure thermal power plants and chemical process industries. Nusselt (1916), who was the pioneering researcher in film condensation, assumed zero shear at the liquid-vapour interface. The external flow of vapour creates interfacial shear which may enhance the condensation heat transfer coefficient, depending on the direction of flow of vapour. Some important investigations on the external flow of vapour over the condenser tube have been made by several researchers (Shekariladge and Gomeluri, 1966; Fujji et al., 1979; Lee et al., 1984; Memory et al., 1993; and Michael et al., 1989). These investigators were primarily concerned with the estimation of condensation heat transfer coefficients under isothermal conditions of the tube wall. Fujji et al. (1972) experimentally investigated the peripheral distribution of wall heat flux and proposed an equation valid for the limiting cases of large and small oncoming vapour velocity. In a later study, Rose (1984) considered the effect of the pressure gradient on forced convection laminar film condensation on a horizontal tube and proposed an equation for the mean heat transfer coefficient. However, in all these investigations, the condensate film was assumed to be in a laminar regime. Honda et al. (1986) experimentally studied downward film condensation of R113 vapour for wide ranges of vapour velocity and condensate temperature differences; some design 
equations were proposed. The experimental data of Michael et al. (1989) on the condensation of steam with high flow velocities could not be correlated satisfactorily by any of the aforementioned theories. It was subsequently suggested that one of the possible reasons for this deviation might be due to the fact that a condensate film can be under a turbulent regime within certain ranges of the system parameters.

For turbulent film condensation on a horizontal cylinder, Sarma et al. (1998) used the eddy diffusivity of Kato's model in the condensate film with an assumption that shear stress at the vapour-liquid interface is on the same order as one would expect for single phase flow. An empirical equation was proposed for an average heat transfer coefficient, which was in good agreement with the experimental data of Honda et al. (1986) and Lin and Yang (2004) who investigated an elliptical condenser tube with variable wall temperature. The non-uniform temperature had an appreciable effect on the local film heat transfer coefficient, but its influence on the mean heat transfer coefficient was minimal. Yang and Lin (2005) considered the non-isothermal condition for the tube wall and interfacial eddy diffusivity. It was observed that the inclusion of the eddy diffusivity effect decreased the mean heat transfer coefficient with an increase in the variation amplitude of the wall temperature. Hu et al. (2006) studied turbulent film condensation on an isothermal inclined elliptical tube in terms of the local condensate film thickness and the heat transfer characteristics. Hu et al. (2007) also studied the influence of different eddy diffusivity models and proposed a new model for local film shear which produced higher mean heat transfer coefficients. However, the abovementioned studies focused on cases of isothermal and non-uniform wall temperature. Hence, the present study aimed at formulating the turbulent film condensation process under the diabatic condition of constant heat flux attributed to the tube wall. In addition, the influence of the external flow of the vapour on the condensate film was included in assessing the performance of the condenser tube. Furthermore, the study included a comparison between the present results and the results obtained from previously published theoretical and experimental data.

\section{PHYSICAL MODEL}

Pure vapours approach a horizontal tube along the direction of the gravity vector. The wall of the condenser tube is maintained at constant heat flux. It is assumed that the condensate film flow is under a turbulent regime in the region away from the upper stagnation point. The influence of boundary layer separation is not considered. The shear stress in the condensate film can be expressed as:

$$
\tau_{w}=\mu\left(1+\frac{\varepsilon_{m}}{v_{1}}\right) \frac{d u}{d y}
$$

For the physical configuration and coordinate system shown in Figure 1, the force balance applied to an element of the condensate is as follows:

$$
\tau_{w}=\tau_{i v}+g \delta \mu\left(\rho_{l}-\rho_{v}\right) \sin \theta
$$

where $\tau_{w}$ and $\tau_{i v}$ are the wall and interfacial shear stresses. 


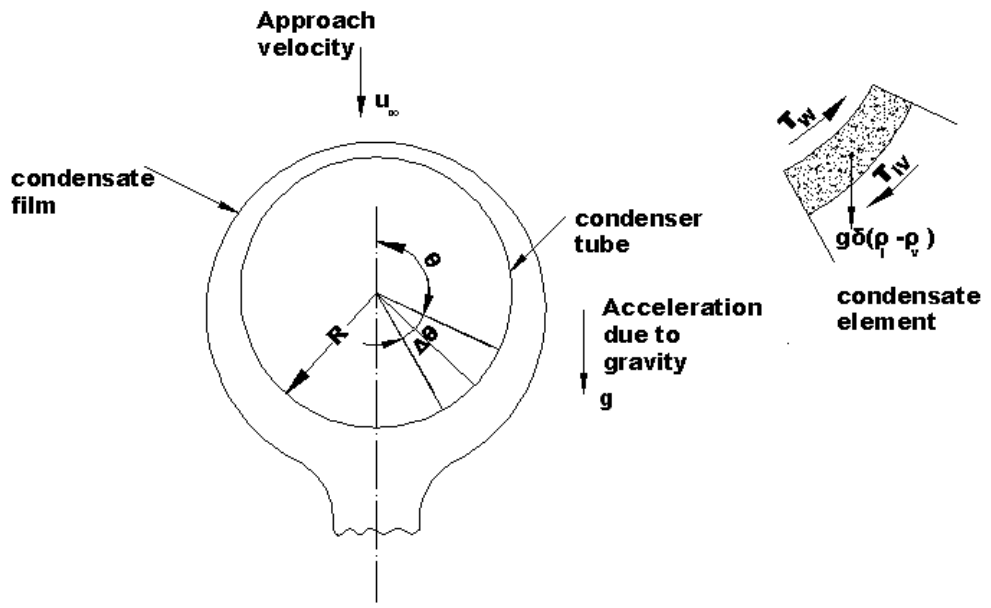

Figure 1. Physical configuration-flow model

\section{Analysis}

The case $\tau_{i v}=0$ happens to be Nusselt's analysis. In Eq. (2), the influence of inertial force is neglected. In addition, considering that the turbulent or eddy conduction across the condensate layer is more significant than the convective component, the equation of conservation of energy in the film is expressed as follows:

$$
\frac{d}{d y}\left[\left(1+\frac{\varepsilon_{m}}{v_{1}} \operatorname{Pr}\right) \frac{d T}{d t}\right]=0
$$

The boundary conditions employed for solving Eq. (3) are as follows:

$$
\begin{array}{lll}
y=0 ; & T=T_{w} \quad(\theta) \text { unknown } \\
y=\delta ; & T=T_{s}
\end{array}
$$

In addition, as per the assumption employed in the analysis:

$$
\left.y=0 ;\left.\quad k_{l} \frac{d T}{d y}\right|_{y=0}=q_{w} \quad \text { (a constant }\right)
$$

The phase transformation occurring at the vapour liquid interface is given by the following relationship:

$$
\frac{d}{d \theta} \int_{0}^{\delta} \rho_{l} u d y=\frac{q_{w} R}{h_{f} g}
$$

Equation (6) implies that the total heat conducted across the condensate film is equal to the value that would arise due to phase transformation occurring at the vapourliquid interface as a result of condensation of vapours around the tube. The expression for convective heat transfer around the cylinder from Holman (1997) is as follows: 


$$
N u=C \operatorname{Re}_{v}^{n} \operatorname{Pr}^{\frac{1}{3}}
$$

The values of $C$ and $n$ were chosen as $C=0.0266$ and $n=0.805$ from Holman (1997), which is valid for the range $40,000<\operatorname{Re}_{v}<400,000$

Further, it was assumed that the principle of Colburn's analogy and the modification of Reynold's analogy holds as well, i.e.:

$$
\frac{f}{2}=S t \operatorname{Pr}^{\frac{2}{3}}
$$

From Eqs. (7) and (8), the average wall friction coefficient $f$ can be obtained as follows:

$$
f=2 C \operatorname{Re}_{v}^{n-1}
$$

Local friction $f_{\theta}$ is further defined by the expression:

$$
f_{\theta}=C\left[\operatorname{Re}_{v}\right] \sin \theta
$$

The average friction coefficient can also be written as:

$$
f=\frac{1}{\pi} \int_{0}^{\pi} f_{\theta} d \theta
$$

Equations (9), (10) and (11) yield the following relationship:

$$
f_{\theta}=\pi C \operatorname{Re}_{v}^{n-1} \sin \theta
$$

The local shear stress is defined by the relationship:

$$
\tau_{i v}=\frac{1}{2} f_{\theta} \rho_{v} u_{T}^{2}
$$

where $u_{T}=2 u_{¥} \sin \theta$ obtained as:

From Eqs. (12). and (13), the expression for local interfacial shear stress can be

$$
\tau_{i v}=2 \pi C r u_{v}^{2} \operatorname{Re}_{v}^{n-1} \sin ^{3} \theta
$$

Thus, it is revealing that the $\tau_{i v}$ induced on the condensate film both at $\theta=0$ and $\pi$ is negligible. It is maximum at $\theta=\pi / 2$.

The wall shear stress can be expressed as:

$$
\tau_{w}=\rho_{l} u^{*^{2}}
$$


Furthermore, the boundary layer separation was ignored in the present analysis. It was close to the assumption employed by Shekriladze and Gomelauri (1966).

With the aid of Eqs. (14) and (15), Equations (2), (3) and (6) are expressed in dimensionless form as follows:

$$
R^{* 3}=R^{*} \varphi F^{(n+1) / 2} \sin ^{3} \theta+\delta^{+} \sin \theta
$$

$$
\frac{d T^{+}}{d y^{+}}=-\left[\frac{1}{R^{*} G r^{\frac{1}{3}}\left(1+\frac{\varepsilon_{m}}{v_{1}} \operatorname{Pr}\right)}\right]
$$

$$
\frac{d}{d \theta} \int_{0}^{\delta^{+}(\theta)} u^{+} d y^{+}=Q \operatorname{Re}_{l}^{\frac{1}{2}}
$$

where $\varphi=\left\{2^{n} \pi C\left[\frac{\rho_{v}}{\rho_{l}}\right] G r^{\frac{3 n-1}{6}}\left[\frac{v_{v}}{v_{l}}\right]^{1-n}\right\}$

From Eqs. (1) and (15), the expression for the velocity profile can be obtained as follows:

$$
\frac{d u^{+}}{d y^{+}}=\frac{1}{1+\frac{\varepsilon_{m}}{v_{1}}}
$$

The normalised boundary conditions for solving Eqs. (17) and (18) are:

$$
\begin{array}{ll}
y^{+}=O ; & T^{+}=T_{w}^{+} \\
y^{+}=\delta^{+} ; & T^{+}=O \\
y^{+}=O ; & u^{+}=O
\end{array}
$$

where $T_{w}{ }^{+}=\frac{k_{l}\left(T_{s}-T_{w}\right)}{q_{w} R}$

According to Sarma et al. (1998), the assumption of universal velocity distribution can be used in the evaluation of the mass flow rate of a condensate at any angular location.

The magnitude of interfacial shear on the vapour-liquid interface is generally assumed to be in terms of a proportionality constant, a factor of multiplication of $\tau_{w}$. In this particular case, the constant of proportionality was tentatively chosen as unity. So, it was assumed that $\tau_{i v}$ is on the same order as $\tau_{w}$, and Eq. (19) can be considered as a valid approximation. In the present study, Kato's expression for eddy diffusivity was used to solve Eqs. (17) and (19). Kato's expression is as follows: 


$$
\frac{\varepsilon_{m}}{v_{1}}=0.4 y^{+}\left[1=\exp \left(-0.0017 y^{+^{2}}\right)\right]
$$

The inadequacy in Eq. (19) is that the influence of interfacial shear is not properly accommodated. However, Eq. (18) requires integrated values of the velocity function; therefore, it is assumed that the introduced error would be marginal.

The local values of wall temperature can be estimated with the aid of the following expression:

$$
S=\left[Q \operatorname{Re}_{l}^{\frac{1}{2}} T_{w}^{+}\right]
$$

Certain observations can be made from Eq. (16). At $\theta \rightarrow 0$ and $\pi$, since $R^{*} \rightarrow 0$, it can be seen that the local value of temperature tends to infinity as per the formula. However, to avoid such a situation and to obtain physically meaningful results at the upper and lower stagnation points, i.e., at $\theta \rightarrow 0$ and $\pi$, the condensation phenomenon is considered, taking into account the special conditions that would prevail at these locations. At $\theta \rightarrow 0$, the effect of the external flow field of vapour on the condensation process can be ignored and is identical to Nusselt's pioneering analysis. According to Nusselt's analysis, under constant heat flux conditions, the sub-cooling parameter is given by the relationship as follows:

$$
\frac{c_{p} \Delta T}{h_{f g} \operatorname{Pr}}=\frac{1}{3}\left[\frac{3 q_{w} R}{\mu_{l} h_{f g}}\right]^{\frac{4}{3}}\left[\frac{\theta}{G r \sin \theta}\right]^{\frac{1}{3}}
$$

It can be seen from Eq. (24) that when $\theta \rightarrow 0$, the sub-cooling parameter $\frac{c_{p} \Delta T}{h_{f g} \operatorname{Pr}}$ tends to a finite value. In addition, when $\theta \rightarrow \pi, \frac{c_{p} \Delta T}{h_{f g} \operatorname{Pr}}$ will attain infinity.

However, from the physical consideration of cylindrical geometry, for a condenser tube with finite wall thickness, the boundary condition $\frac{d s}{d \theta}$ at $\theta=\pi$ holds. This boundary condition will lead the wall temperature to a finite value. In the present problem, the sub-cooling parameter can be assessed with the imposition of the condition that laminar film condensation theory holds at the upper stagnation point, i.e. $\theta=0$. However, at the lower stagnation point, i.e. $\theta=\pi$, the condition of symmetry viz. $\frac{d s}{d \theta}$ is assumed to hold such that the sub-cooling parameter tends to a finite value. follows:

By definition, the local condensation heat transfer coefficient can be written as

$$
q_{w}=\left.k_{l} \frac{\partial T}{\partial y}\right|_{y=0}=h\left(T_{s}-T_{w}\right)
$$


Equation (25) in dimensionless form can be expressed by the relationship:

$$
\frac{N u}{\operatorname{Re}_{l}^{\frac{1}{2}}}=\frac{Q}{S}
$$

Furthermore, the mean Nusselt number and wall temperature are obtained from the following expression:

$$
\begin{aligned}
\frac{\bar{N} u}{\operatorname{Re}_{l}^{\frac{1}{2}}} & =\frac{1}{\pi} \int_{0}^{\pi} N u d \theta \\
\bar{S} & =\frac{1}{\pi} \int_{0}^{\pi} S d \theta
\end{aligned}
$$

In writing down Eq. (19), there is an implied assumption that $\tau_{i v}$ is on the same order as $\tau_{w}$. It is presumed that such an assumption will not lead to substantial error in the estimation of the integral appearing in Eq. (18). In other words, a universal velocity distribution is being used in the estimation of discharge rate of the condensate at any angular location. In fact, it can be seen that at very high velocities of the external flow of vapour, such an assumption, i.e. $\tau_{i v} \rightarrow \tau_{w}$ is valid and hence Eq. (19) can be considered as a valid approximation.

Thus, it is evident that the local condensation heat transfer coefficients are dependent on the following system parameters:

$$
\frac{N u}{\operatorname{Re}_{l}^{\frac{1}{2}}}=F[\theta, \varphi, F r, G r, Q]
$$

\section{Solution Procedure}

1. The system pressure, the approach velocity $\mathrm{u}_{\infty}$, the diameter of the condenser tube and the thermal load are considered as input parameters. Thus, $F r, Q$ and $G r$ can be computed.

2. To begin the calculation, the dimensionless film thickness $\delta^{+}$and the velocity $\mathrm{u}^{+}$ in the condensate film are assumed to be zero at $\theta=0$, i.e. node $m=1$. The temperature is evaluated from Eq. (17) iteratively with an initial guess for $T_{w}{ }^{+}$so that the boundary condition $T^{+}=T_{w}^{+}$at $y^{+}=0$ and $T^{+}=0$ at $y^{+}=\delta^{+}$are satisfied for a prescribed accuracy of $10^{-5}$.

3. The velocity profile across the condensate film and angular positions $\theta$ and $R^{*}$ are obtained by solving Eqs. (16), (17) and (18).

By proceeding to the next node $m=m+1$, i.e. at $m=2$, the condensate film thickness $d^{+}(m+1)=d^{+}(m)+d d^{+}$, where $d d^{+}$is assumed be 0.003 . Equation (18) is written in finite difference form to evaluate the angular position $\theta$. 


$$
d \theta=\left[\frac{I\left(\delta^{+}+d \delta^{+}\right)-I\left(\delta^{+}\right)}{Q \operatorname{Re}^{\frac{1}{2}}}\right] \quad \text { where } I\left(\delta^{+}\right)=\int_{0}^{\delta^{+}(\theta)} u^{+} d y^{+}
$$

The value $\delta^{+}$is incremented by $d d^{+}$and steps 2 and 3 are repeated to determine the angular position, $R^{*}$ and $T_{w}^{+}$. Equation (26) is used to solve the local Nusselt number. The procedure outlined in step 3 is repeated until $\theta$ advances to $\pi$. Equation (27) is further utilised to determine the average values of the heat transfer coefficient and wall temperatures.

\section{RESULTS AND DISCUSSION}

A series of numerical calculations were performed on the model (Figure 1), to investigate the behaviour of turbulent film condensation of pure vapours over a horizontal cylinder with constant heat flux at the tube wall.

\section{Characteristics of Flow Hydrodynamics}

The variation of the condensate film thickness $\delta^{+}$around the periphery is shown plotted in Figure 2 for different values of $Q$. It is evident that the condensate film thickness increases monotonically with an increase in $Q$.

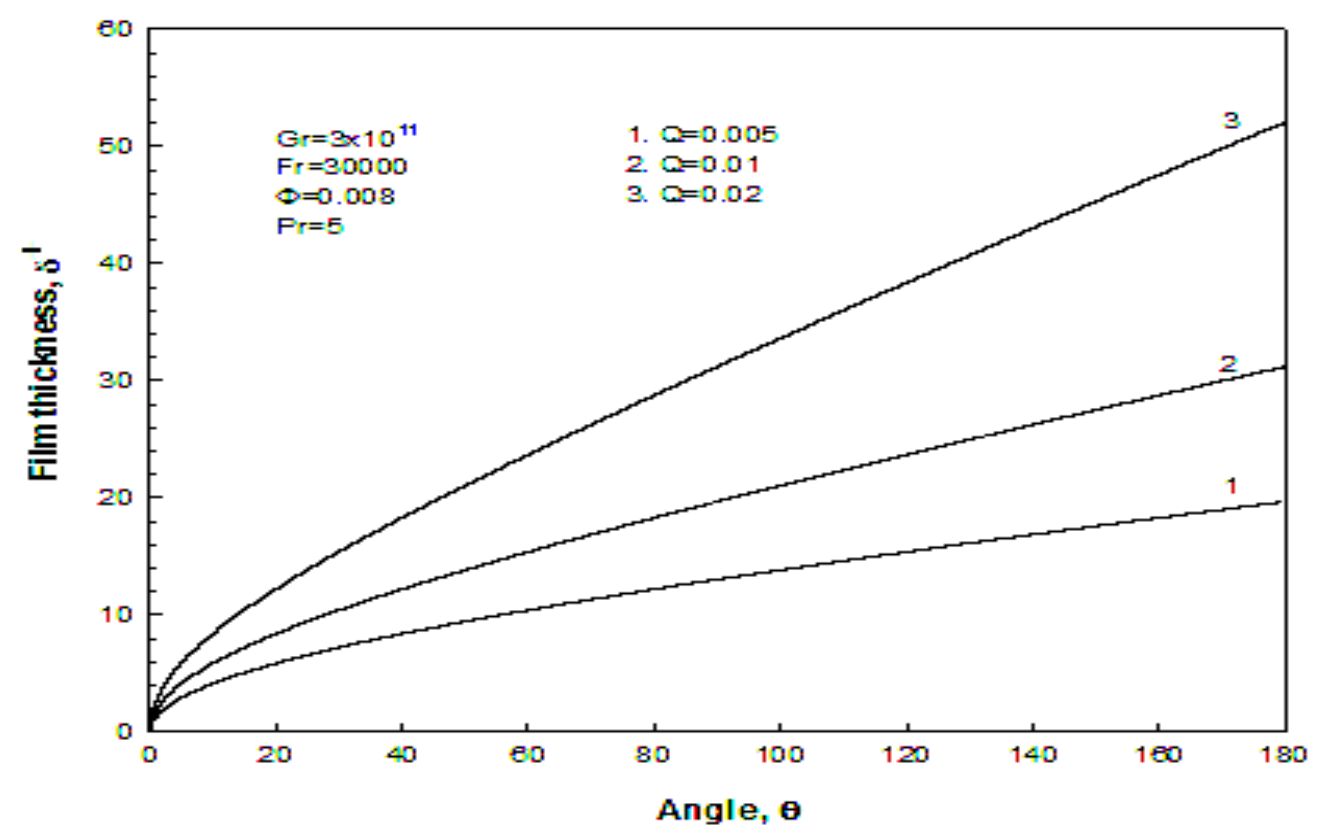

Figure 2. Variation in condensate film thickness around the periphery

Figure 3 reveals the variation of shear along the tube wall for various values of the interfacial shear parameter $\varphi$. The parameter $\varphi$ consists of the vapour-to-liquid density and viscosity ratios. Thus, parameter $\varphi$ signifies the effect of system pressure. It can be observed from Figure 3 that the wall shear increases with an increase in system pressure. 


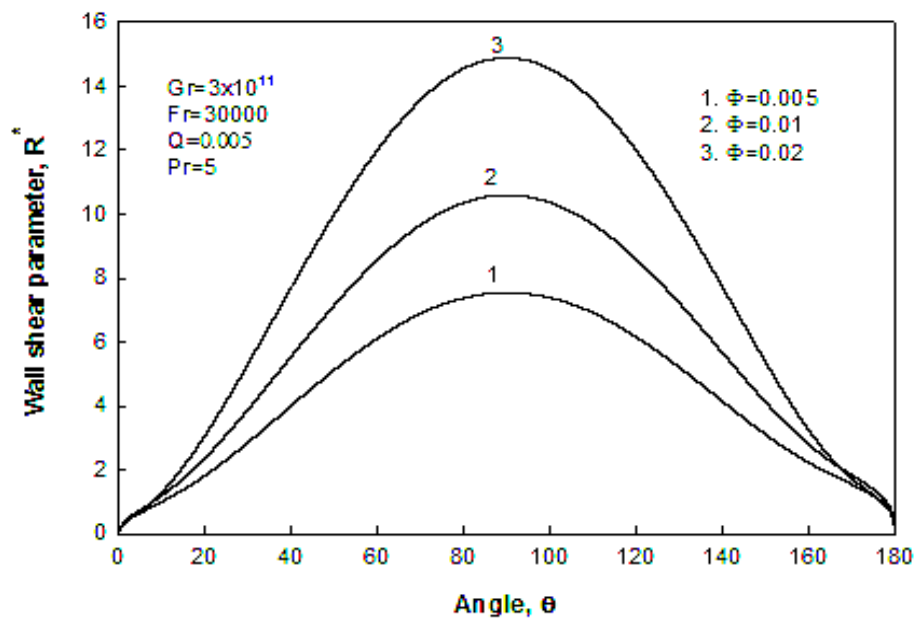

Figure 3. Variation in shear at the tube wall around the periphery; effect of interfacial shear

\section{Heat Transfer Characteristics}

\section{Effect of the Sub-cooling Parameter (S)}

The constant heat flux condition at the tube wall makes the surface highly non-isothermal. Figure 4 demonstrates the variation in the sub-cooling parameter $S$ for various values of the thermal load parameter $Q$. It can be inferred from Figure 4 that the wall temperature $T_{w}$ increases up to $\theta=\pi / 2$ and subsequently decreases. It can be noted that the wall temperature $T_{w}$ decreases as the surface heat flux or cooling rate is increased.

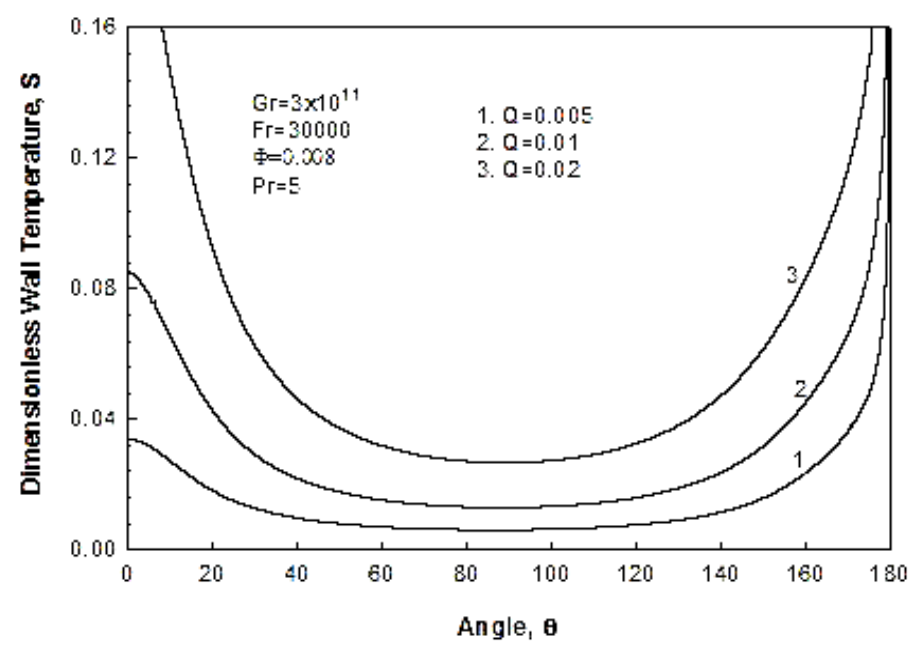

Figure 4. Wall temperature variation around the periphery

\section{Influence of Thermal Load on the Local Heat Transfer Coefficient}

Equation (26) is shown plotted in Figure 5 for various values of Q. It is evident that the rise and decay characteristics of the local Nusselt number indicates that the condensate heat transfer coefficients attain a maximum value at approximately $\theta=88^{\circ}$. Further, as $\theta \rightarrow \pi$, the condensate heat transfer coefficient decreases considerably. 


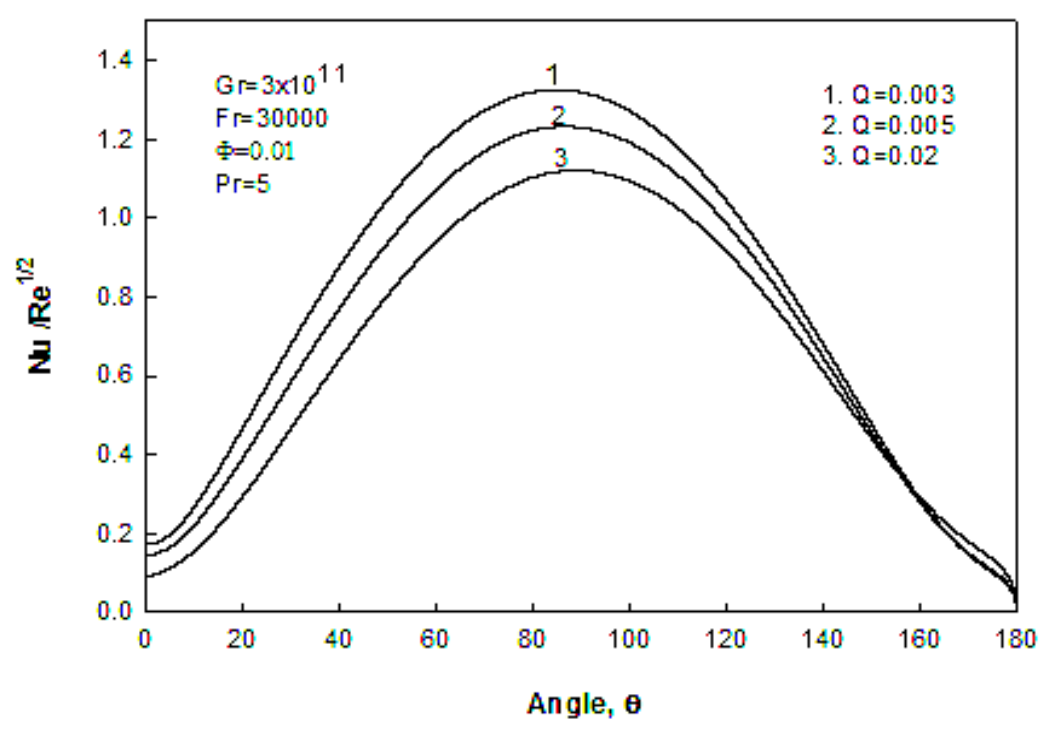

Figure 5. Variation in the local Nusselt number around the periphery; effect of $Q$

\section{Effect of External Vapour Velocity}

The effect of the vapour Froude number on the condensate Nusselt number is shown in Figure 6. It can be observed that the Nusselt number increases with an increase in vapour velocity $u_{\infty}$. Furthermore, there is a decrease in the Nusselt number with an increase in $Q$, which is due to an increase in the condensate film thickness.

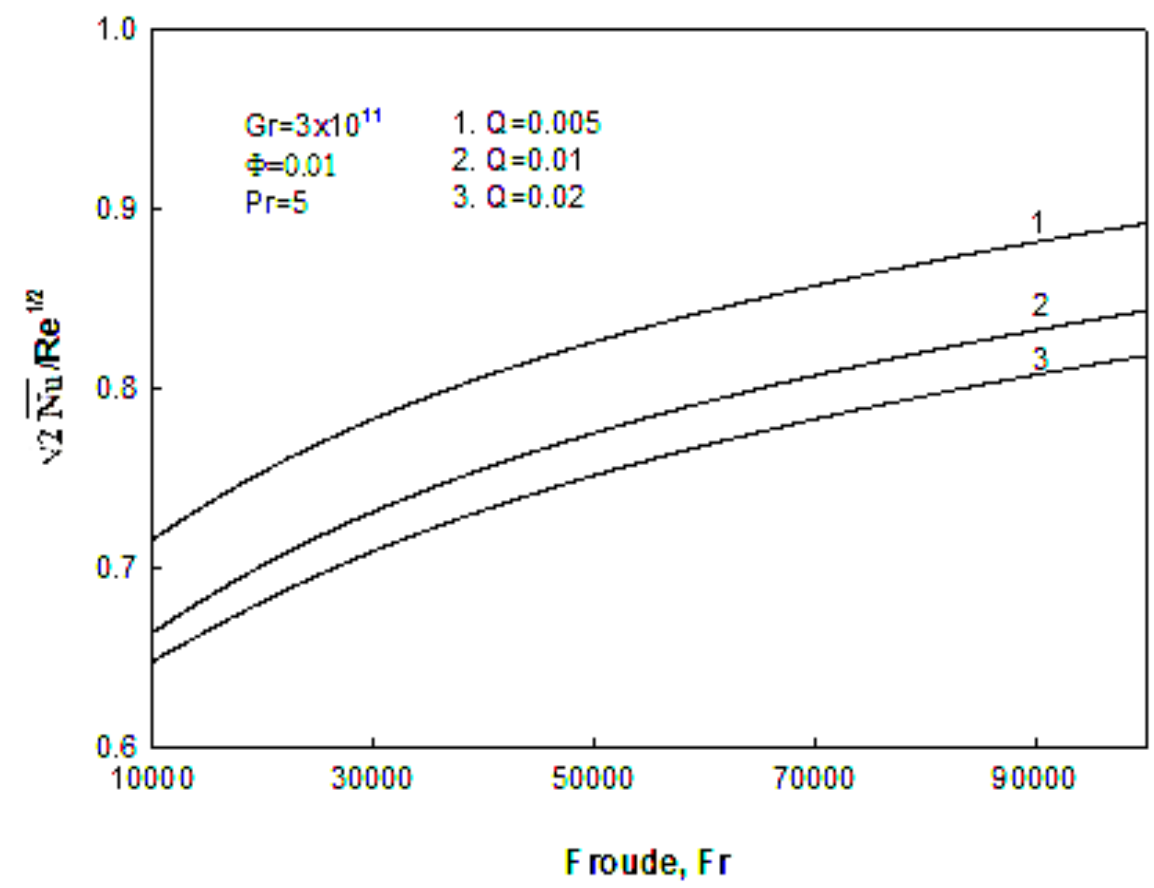

Figure 6. Effect of external flow on the mean condensate heat transfer coefficients 


\section{Effect of Thermal Load, $Q$}

An interesting phenomenon is observed in Figure 7, in which the average Nusselt number $\left(\overline{\mathrm{Nu}} / \mathrm{Re}^{1 / 2}\right)$ is shown plotted as a function of the dimensionless heat flux $Q$ for different Froude numbers. At higher Froude numbers, as the heat flux increases, the Nusselt number is found to decrease initially and later assumes an asymptotic value. In other words, the average condensation heat transfer coefficient assumes an asymptotic value as the wall heat flux $\left(q_{w}\right)$ is increased. However, at lower Froude numbers such as $F r=10,000$, the condensation heat transfer coefficient is found to increase at higher wall heat fluxes due to increased condensation Reynold's numbers.

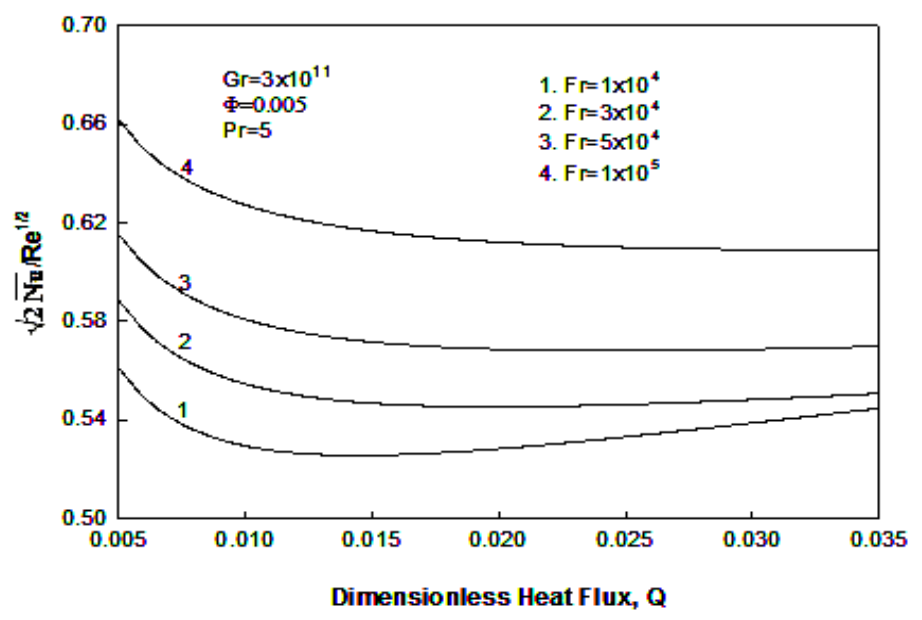

Figure 7. Effect of dimensionless heat flux on mean condensate Nusselt number; influence of the Froude number

The variation in the Nusselt number with $Q$ is shown in Figure 8 for different values of the shear parameter $\varphi$. It was found that the average Nusselt number increases with an increase in the shear parameter at any given value of $Q$.

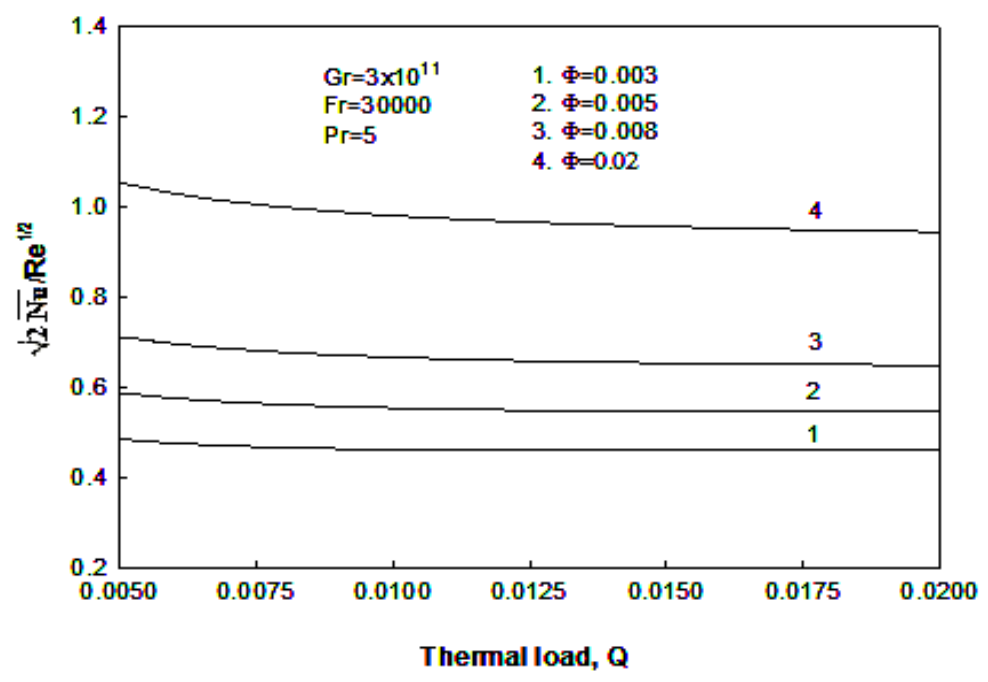

Figure 8. Effect of dimensionless heat flux on the mean condensate Nusselt number; influence of interfacial shear 


\section{Effect of Shear Parameter, $\varphi$}

The effect of the Prandtl number on the Nusselt number is shown in Figure 9 for different values of $F r$ and $\varphi$. It was found that the Nusselt number increases with an increase in Prandtl number of the condensate. The condensation heat transfer coefficient also increases with an increase in either the Froude number or interfacial shear.

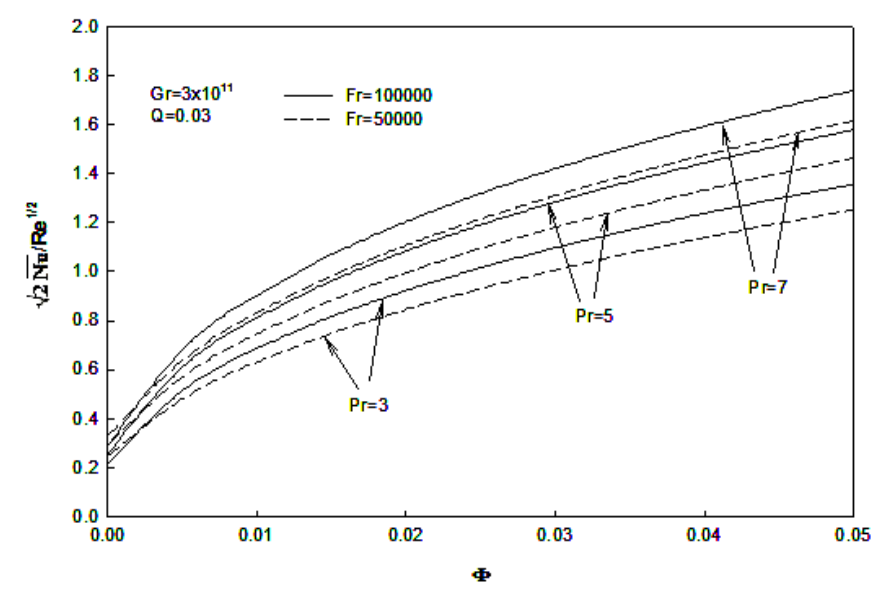

Figure 9. Effect of the shear parameter on the mean condensate Nusselt number

\section{Effect of Inverse Vapour Velocity, F}

The analysis was validated using the experimental data of Michael et al. (1989), shown in Figure 10. The shear parameter $\varphi$ comprises the physical properties of the condensate and the condenser tube diameter. The ranges of $\varphi$ corresponding to experimental values will be in the range $0.003 \leq \varphi \leq 0.006$ (i.e. system pressure between 0.006 and 0.04 bar); these magnitudes were computed for the range of the experimental data employed for comparison with the present theory. The present theoretical analysis agrees satisfactorily with the data for steam. Furthermore, the analytical results of Shekriladze and Gomelauri (1966), Rose (1984), Honda et al. (1986) and Sarma et al. (1998) are also shown plotted for comparison in Figure 10.

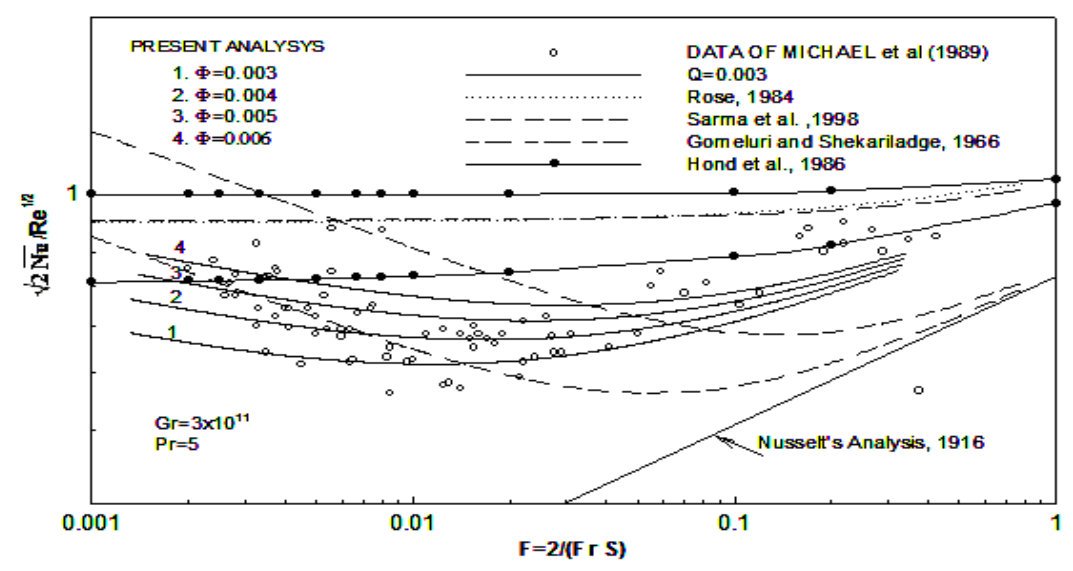

Figure 10. Comparison of the present theory with published experimental data. 


\section{GENERALISED CORRELATION}

The theoretical results of the present analysis for wide ranges of different system parameters were subjected to non-linear regression; the following equation for the average Nusselt number is proposed:

$$
\frac{\overline{N u_{t}}}{R e^{1 / 2}}=0.8732 \frac{\varphi^{0.3124}}{(F \bar{S})^{0.03376} \mathrm{Q}^{0.1306}}
$$

Equation (29) is valid for the following ranges of parameters: $0.001<\varphi<0.06$ and 0.001 $<Q<0.02$. Furthermore, Eq. (29) fits the theoretical results with a standard deviation of $5 \%$.

The lowest possible limiting value of the Nusselt number is obtained when the vapour is stagnant and condensate film is in the laminar flow. The Nusselt's equation for the condensation Nusselt number in the case of laminar film condensation over a horizontal cylinder can be conveniently expressed in the following form:

$$
\frac{\overline{N u}_{\text {lam }}}{\operatorname{Re}^{1 / 2}}=0.4103 \frac{(F \bar{S})^{1 / 3}}{\mathrm{Q}^{1 / 3}}
$$

Thus, from Eqs. (29) and (30), one can predict the mean condensate heat transfer coefficients for different ranges of vapour velocity from the following relationship:

$$
\overline{N u}^{3}=\left[\overline{N u}_{\text {lam }}^{3}+\overline{N u}_{t}^{3}\right]
$$

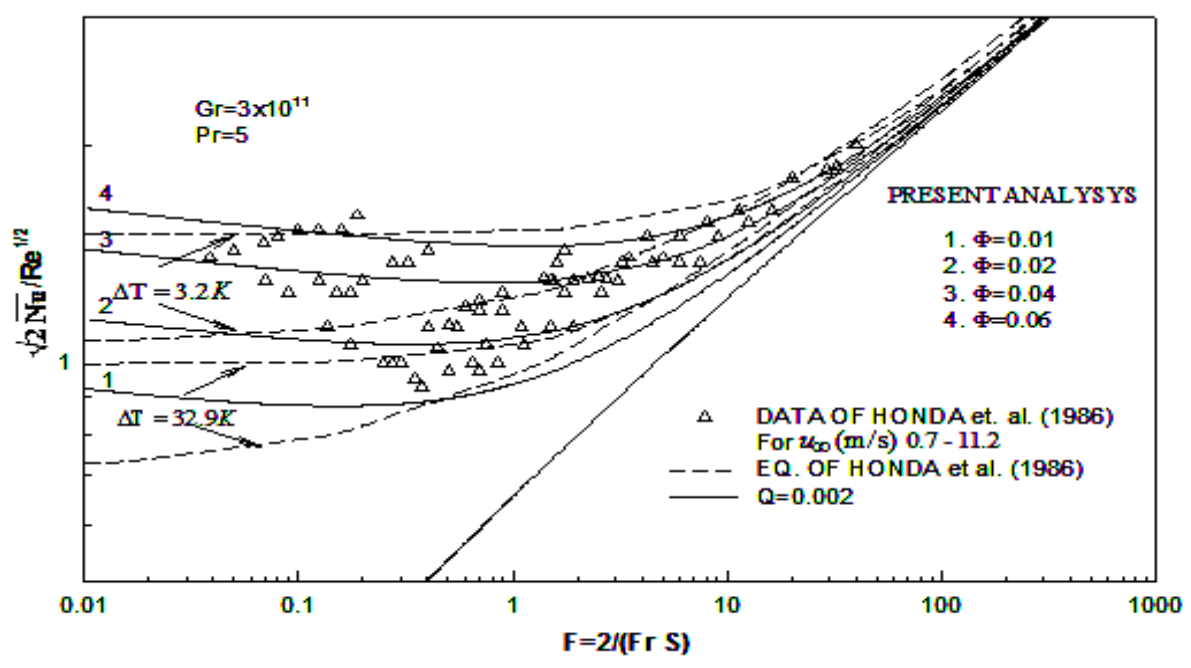

Figure 11. Comparison of present analysis with the data of Honda et al. (1986)

Equation (31) of the present analysis is shown plotted together with the experimental data for R-113 in Figure 11. It can be seen that the explicit form of Eq. (31) satisfactorily correlates the experimental data with reasonable accuracy. Hence, Eq. (31) can be used for design purposes. The comparison of theoretical results for different values 
of $\varphi$ with the experimental data of Michael et al. (1989) and Honda et al. (1986), shown in Figures 10 and 11, respectively, clearly indicate the effect of interfacial shear on the condensation of flowing vapour over a horizontal cylinder. Hence, the interfacial shear has been shown in this study to be a strong function of system pressure.

\section{CONCLUSIONS}

1. The comparison of present analytical results with the available experimental and theoretical data in the literature confirms that the present theory is satisfactory for predicting condensation characteristics.

2. The thermal loading of the condenser tube has an optimal value and increase in flow rate beyond a certain value has no practical significance. It merely increases the pumping power.

3. An increase in approach velocity enhances the mean hear transfer coefficient.

4. The system pressure has a profound influence on the condensation heat transfer coefficient, which was highlighted in the present study by the interfacial shear parameter $\varphi$.

5. A generalised correlation Eq. (29) for average condensate heat transfer coefficient is obtained for high vapour velocities with a standard deviation of $5 \%$.

6. Equation (31) was found to be in good agreement with the condensation of vapours of R-113 as shown by Honda et al. [5]. Therefore, Eqs. (29) and (30) in the form of Eq. (31) can be used for the design of condensers for a wide range of system parameters.

\section{ACKNOWLEDGEMENTS}

The first author thanks Prof. Soma Raju of the GVP College of Engineering, Visakhapatnam for providing facilities in preparation of this article and also Mr. Someswara Rao, IIT, Chennai.

\section{REFERENCES}

Fujii, T., Honda, H. and Oda, K. 1979. Condensation of steam on a horizontal tube the influence of oncoming velocity and thermal condition at the tube wall. Condensation Heat Transfer, 35-43.

Fujii, T., Uehare, H. and Kurata, C. 1972. Laminar filmwise condensation of flowing vapor on a horizontal tube. International Journal of Heat and Mass Transfer, 15: 235-246.

Holman, J.P. 1997. Heat Transfer. $8^{\text {th }}$ ed. New York: McGraw-Hill.

Honda, H., Nozu, S., Uchima, B. and Fujii, T. 1986. Effect of vapor velocity on film condensation of R-113 on horizontal tubes in a cross flow. International Journal of Heat and Mass Transfer, 29: 429-438.

Hu, H.P. and Chen, C.K. 2006. Simplified approach of turbulent film condensation on an inclined elliptical tube, International Journal of Heat and Mass Transfer, 49: 640-648

Hu, H.P. and Chen, C.K. 2007. Effects of eddy diffusivity in film condensation on a horizontal tube. International Communications in Heat and Mass Transfer, 34: 52-61.

Lee, W.C., Rahbar, S. and Rose, J.W. 1984. Film condensation of refrigerant 113 and 
ethanediol on a horizontal tube-effect of vapor velocity. ASME Journal of Heat Transfer, 106: 524-530.

Lin, Y.T. and Yang, S.A. 2004. Turbulent film condensation on a horizontal elliptical tube with variable wall temperature. Journal of Marine Science and Technology, 12: 300-308.

Memory, S.B., Lee, W.C. and Rose, J.W. 1993. Forced convection film condensation on a horizontal tube- effect of surface temperature variation. International Journal of Heat and Mass Transfer, 36: 1671-1676.

Michael, A.G., Rose, J.W. and Daniels, L.C. 1989. Forced convection condensation on a horizontal tube - experimental with vertical downflow of steam. ASME Journal of Heat Transfer, 111: 792-797.

Nusselt. 1916. Die Oberflachenkondensation des Wasserdampfes, Z. Ver. Dt. Ing. 60: 541-546.

Rose, J.W. 1984. Effect of pressure gradient in forced film condensation on a horizontal - tube effect of surface temperature variation, International Journal of Heat and Mass Transfer, 27: 39-47.

Sarma, P.K., Vijayalakshmi, B., Mayinger, F. and Kakac, S. 1998. Turbulent film condensation on a horizontal tube with external flow of pure vapors. International Journal of Heat and Mass Transfer, 41: 537-545.

Schlichting. 1979. Flow past a circular cylinder, in: Boundary Layer Theory, $7^{\text {th }}$ ed., New York: McGraw-Hill.

Shekriladze, I.G. and Gomelauri, V.I. 1966. Theoretical study of laminar film condensation of flowing vapor. International Journal of Heat and Mass Transfer, 9: 581-591.

Yang, S.A. and Lin, Y.T. 2005. Turbulent film condensation on a non-isothermal horizontal tube-effect of eddy diffusivity. Applied Mathematical Modeling 29: 1149-1163.

\section{Nomenclature}

$C_{p} \quad$ specific heat capacity of the condensate

D diameter of the horizontal tube

F dimensionless inverse vapour velocity, $F=(2 / F r \bar{S})$

$\mathrm{f} \quad$ average friction coefficient

$\mathrm{f}_{\theta} \quad$ local friction coefficient

Fr Froude number, $u_{\infty}^{2} / g R$

Gr Grashof number, $\left(\frac{g R^{3}}{v_{1}^{2}}\right)\left(\frac{\rho_{l}-\rho_{v}}{\rho_{l}}\right)$

$\mathrm{g} \quad$ acceleration due to gravity

$\mathrm{h}$ condensation heat transfer coefficient

$\mathrm{h}_{\mathrm{fg}} \quad$ latent heat

$\mathrm{k}$ thermal conductivity

$\mathrm{Nu} \quad$ Nusselt number, $h R / k_{l}$

$\overline{\mathrm{Nu}} \quad$ mean Nusselt number

Pr Prandtl number

$\mathrm{q}_{\mathrm{w}} \quad$ wall heat flux 
Q dimensionless heat flux, $\left(\frac{q_{w} R}{\mu_{l} h_{h g}} \operatorname{Re}_{l}^{-\frac{1}{2}}\right)$

$\mathrm{R} \quad$ outer radius of the tube

$\mathrm{R}^{+} \quad$ shear radius, $\left(R u^{*} / v_{l}\right)$

$\mathrm{R}^{*} \quad$ wall shear parameter, $\left(R^{+} / G r^{1 / 3}\right)$

$\operatorname{Re}_{1} \quad$ liquid Reynolds number, $\left(u_{\infty} R / v_{l}\right)$

$\operatorname{Re}_{\mathrm{v}} \quad$ vapour Reynolds number, $\left(u_{\infty} D / v_{l}\right)$

$\mathrm{S} \quad$ sub-cooling parameter, $\left[c_{p}\left(T_{s}-T_{w}\right) / h_{f g} \operatorname{Pr}\right\rfloor$

$\bar{S} \quad$ average dimensionless wall temperature

St Stanton number

$\mathrm{T}$ temperature

$\mathrm{T}^{+} \quad$ dimensionless temperature, $T^{+}=k_{l}\left(T_{s}-T_{w}\right) / q_{w} R$

$\mathrm{u} \quad$ velocity along the wall

$u_{\infty} \quad$ approach velocity of steam

$u_{T} \quad$ tangential velocity of steam

$\mathrm{u}^{*} \quad$ shear velocity

$\mathrm{u}^{+} \quad$ dimensionless velocity, $\left(u / u^{*}\right)$

y distance normal to the wall

$\mathrm{y}^{+} \quad$ dimensionless distance, $\left(y u^{*} / v_{l}\right)$

\section{Greek symbols}

$\delta \quad$ condensate film thickness

$\delta^{+} \quad$ dimensionless film thickness, $\left(\delta u^{*} / v_{l}\right)$

DT temperature difference, $\left(T_{s}-T_{w}\right)$

$\varepsilon_{m} \quad$ momentum eddy diffusivity

$q \quad$ angle measured from the upper stagnation point

$\mu \quad$ absolute viscosity

$v \quad$ kinematic viscosity

$\rho$ density

$\tau \quad$ shear stress

$\varphi \quad$ shear parameter

\begin{tabular}{ll}
\multicolumn{2}{l}{ Subscripts } \\
iv & vapour-liquid \\
l & liquid \\
lam & laminar \\
S & saturation \\
t & turbulent \\
v & vapour \\
W & wall
\end{tabular}

